\title{
Effect of acarbose, pectin, a combination of acarbose with pectin, and placebo on postprandial reactive hypoglycaemia after gastric surgery
}

\author{
P A J SPETH, J B M J JANSEN, AND C B H W LAMERS \\ From the Division of Gastroenterology, St Radboud Hospital, University of Nijmegen, Nijmegen, The \\ Netherlands
}

SUMMARY In a double-blind study we have compared the effect of $50 \mathrm{mg}$ acarbose, $100 \mathrm{mg}$ acarbose, $4.2 \mathrm{~g}$ pectin, a combination of $50 \mathrm{mg}$ acarbose with $4.2 \mathrm{~g}$ pectin, and placebo on plasma glucose, plasma insulin, breath hydrogen and hypoglycaemic symptoms after a normal carbohydrate rich meal in nine patients with previous gastric surgery. Fifty milligrams acarbose, $100 \mathrm{mg}$ acarbose and the combination of $50 \mathrm{mg}$ acarbose with $4.2 \mathrm{~g}$ pectin significantly inhibited the postprandial peak glucose concentration $(\mathrm{p}<0.01)$. The lowest plasma glucose concentration, observed 60-150 minutes after ingestion of the meal, was significantly increased by the addition of $50 \mathrm{mg}$ acarbose $(\mathrm{p}<0.01)$ and the combination of acarbose with pectin $(\mathrm{p}<0.05)$. The combination of acarbose with pectin was the only treatment that significantly inhibited the plasma insulin peak $(\mathrm{p}<0 \cdot 05)$. Eight of nine patients had symptoms of hypoglycaemia on placebo, two on $50 \mathrm{mg}$ acarbose $(\mathrm{p}<0.05)$, two on $100 \mathrm{mg}$ acarbose $(\mathrm{p}<0.05)$, five on pectin $(\mathrm{ns})$, and two on the combination of acarbose and pectin $(\mathrm{p}<0 \cdot 05)$. All treatments with acarbose induced significant increases in breath hydrogen excretion $(\mathrm{p}<0.05)$.

Postprandial reactive hypoglycaemia may occur in patients with previous gastric surgery. ${ }^{1-3}$ This postprandial hypoglycaemia is thought to be because of the rapid gastric emptying of a carbohydrate meal into the small intestine inducing rapid absorption of glucose followed by reactive hyperinsulinism and subsequent hypoglycaemia. ${ }^{1-3}$ It has been shown recently that $100 \mathrm{mg}$ acarbose, an $\alpha$-glucoside hydrolase inhibitor (Bayer, BAY g 5421), induced a significant increase in the lowest plasma glucose concentration after an oral dose of $50 \mathrm{~g}$ sucrose in five patients with reactive hypoglycaemia after gastric surgery. ${ }^{4}$ Although not presented in that study, it is very likely that such a high dose of acarbose will induce serious side-effects due to malabsorption of carbohydrates. ${ }^{5,6}$ On the other hand, it has previously been reported that addition of $14.5 \mathrm{~g}$ of pectin to a $50 \mathrm{~g}$ oral glucose load prevented the occurrence of hypoglycaemic symptoms and induced a significant increase in the lowest postprandial glucose concentration in nine patients with previous gastric surgery. ${ }^{3} 14.5 \mathrm{~g}$ of

Address for correspondence to: Dr C Lamers, Division of Gastroenterology. St Radboud Hospital, 6500 HB Nijmegen. The Netherlands.

Received for publication 12 November 1982 pectin is, however, an extremely high dose and it is very unlikely that this dose of pectin is tolerated by patients on chronic treatment.

The present study was undertaken to determine whether a low dose of $50 \mathrm{mg}$ acarbose is effective in reducing hypoglycaemic symptoms and influencing laboratory measurements after ingestion of a normal carbohydrate rich meal in patients with symptoms of postprandial reactive hypoglycaemia after gastric surgery, and to compare the effect of $50 \mathrm{mg}$ acarbose with a higher dose of acarbose, with a relatively low dose of pectin and with the combination of acarbose with pectin. Therefore, we have compared in a double blind study the effect of $50 \mathrm{mg}$ acarbose, $100 \mathrm{mg}$ acarbose, $4.2 \mathrm{~g}$ pectin, a combination of $50 \mathrm{mg}$ acarbose with $4.2 \mathrm{~g}$ pectin and placebo on plasma glucose, plasma insulin, breath hydrogen and hypoglycaemic symptoms after a standardised carbohydrate rich breakfast in patients with symptoms of postprandial hypoglycaemia after gastric surgery.

\section{Methods}

PATIENTS

Nine patients, eight men and one woman, mean age 
44 years with a range of 28 to 52 years, were studied. Seven had undergone partial gastrectomy with gastrojejunostomy (Billroth II) and two truncal vagotomy with pyloroplasty between three and 19 (average 9.5) years before this study. Two patients were previously treated by interposition of an inversed jejunal segment without significant improvement of symptoms. The patients were selected on the basis of (1) a history of symptoms suggestive of postprandial reactive hypoglycaemia, (2) a plasma glucose concentration of less than 3.0 $\mathrm{mmol} / \mathrm{l}$ at least 60 minutes after oral ingestion of $50 \mathrm{~g}$ glucose per $\mathrm{m}^{2}$ body surface, and (3) hypoglycaemic symptoms at least 60 minutes after the oral glucose load.

After an overnight fast the patients ingested within 15 minutes a standard breakfast containing three slices of bread with $20 \mathrm{~g}$ butter, $42 \mathrm{~g}$ marmalade, and $10 \mathrm{~g}$ sugar, $100 \mathrm{ml}$ tea containing 10 g sugar, and $150 \mathrm{ml}$ milk. In total the breakfast contained $88 \mathrm{~g}$ carbohydrate, $18.5 \mathrm{~g}$ fat and $11 \mathrm{~g}$ protein, together 2350 Joules ( 560 Calories). During each breakfast the patients ingested in random order and in a double-blind fashion two tablets containing either $50 \mathrm{mg}$ acarbose each, or one placebo and one $50 \mathrm{mg}$ acarbose, or both placebo, and six large capsules containing $0.7 \mathrm{~g}$ pectin each or placebo. Acarbose (BAY g 5421) was obtained from Bayer Clinical Research Benelux, Mijdrecht, The Netherlands, and pectin from Pomosin, Bunschoten, The Netherlands. The studies were performed at least two days apart. Blood samples were drawn at -15 , $0,15,30,45,60,90,120,150$, and 180 minutes through an Abbocath ${ }^{\mathrm{R}}$ needle perfused with $0.9 \%$ saline. Plasma glucose was measured by the method of $\mathrm{Hoffman}^{7}$ and plasma insulin by radioimmunoassay. ${ }^{8}$ At the same time intervals end-expiratory gas samples were obtained for analysis of breath hydrogen. ${ }^{9}$ In addition, we studied whether the patients had hypoglycaemic symptoms during the period 60 to 150 minutes after ingestion of the meal.

All patients gave informed consent. Results were expressed as mean \pm 1 SEM. Statistical analysis was performed by non-parametric tests (Wilcoxon's and sign test). ${ }^{10}$

\section{Results}

Ingestion of the meal together with the placebo tablets and placebo capsules induced symptoms of reactive hypoglycaemia in eight patients. Peak plasma glucose concentrations were $8.6 \pm 0.5 \mathrm{mmol} / 1$ with a range of 6.3 to $12.0 \mathrm{mmol} / \mathrm{l}$. Hypoglycaemia ranged from 1.1 to $3.7 \mathrm{mmol} / \mathrm{l}$ with a mean value of $2.6 \pm 0.3 \mathrm{mmol} / \mathrm{l}$ (Figure; Table). Two patients had very high peak plasma insulin concentrations of 313
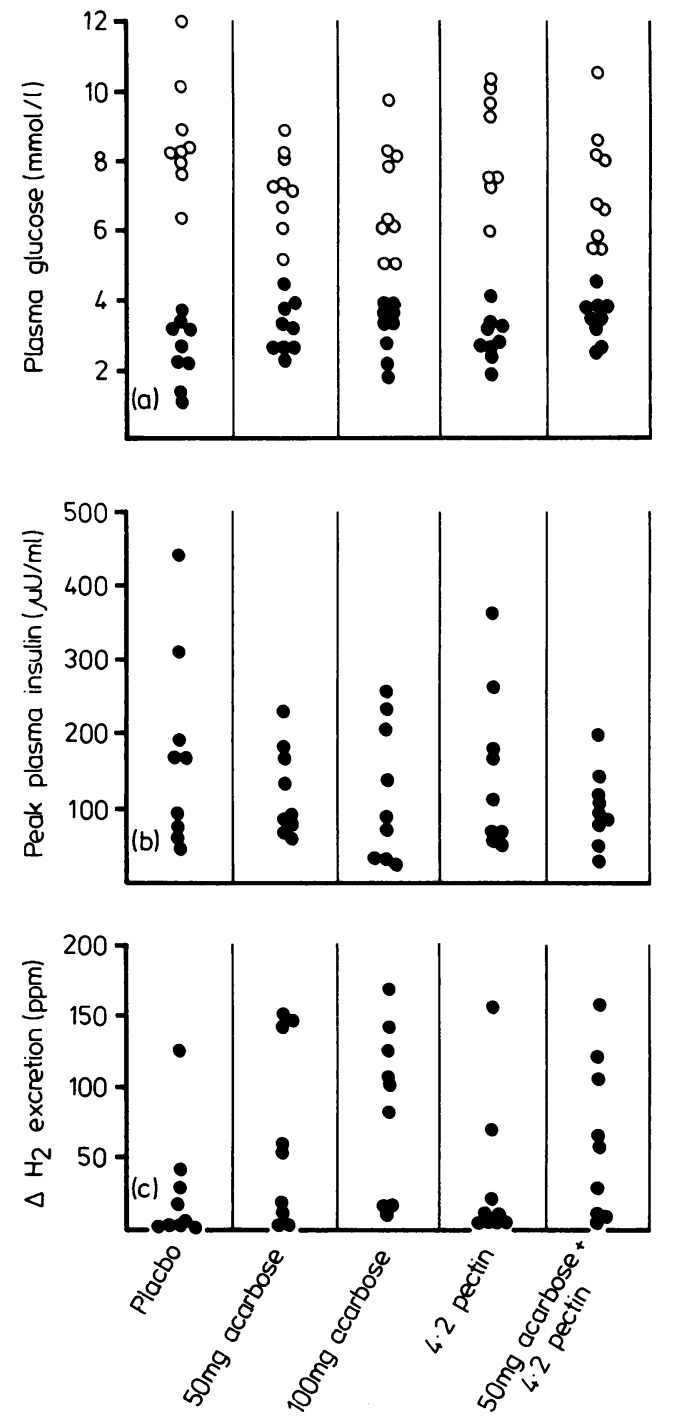

Figure Effect of placebo, $50 \mathrm{mg}$ acarbose, $100 \mathrm{mg}$ acarbose, $4.2 \mathrm{~g}$ pectin, and combination of $50 \mathrm{mg}$ acarbose with $4 \cdot 2 \mathrm{~g}$ pectin on peaks and nadirs of plasma glucose (upper panel), peak plasma insulin (middle panel), and rise in breath hydrogen excretion (lower panel), in nine patients with previous gastric surgery. The open circles denote glucose peaks and the closed circles glucose nadirs.

and $442 \mu \mathrm{U} / \mathrm{ml}$, while three patients showed an exaggerated rise in breath hydrogen excretion of more than $25 \mathrm{ppm}$ (Table; Figure).

After addition of $50 \mathrm{mg}$ acarbose to the meal only two of the patients experienced hypoglycaemic symptoms $(p<0.05)$. Furthermore, this treatment 
Table Effect of placebo, $50 \mathrm{mg}$ acarbose, $100 \mathrm{mg}$ acarbose, $4.2 \mathrm{~g}$ pectin, and the combination of $50 \mathrm{mg}$ acarbose with $4.2 \mathrm{~g}$ pectin on plasma glucose, plasma insulin, breath hydrogen excretion and hypoglycaemic symptoms after carbohydrate-rich meal in nine patients with previous gastric surgery

\begin{tabular}{|c|c|c|c|c|c|}
\hline & \multicolumn{2}{|c|}{ Glucose (mmolll) } & \multirow{2}{*}{$\begin{array}{l}\text { Insulin peak } \\
\mu U / m l\end{array}$} & \multirow{2}{*}{$\begin{array}{l}\text { Breath hydrogen } \\
\text { after } 180 \mathrm{~min} \\
\text { ppm }\end{array}$} & \multirow{2}{*}{$\begin{array}{l}\text { Patients with } \\
\text { hypoglycaemic } \\
\text { symptoms (no) }\end{array}$} \\
\hline & Highest & Lowest & & & \\
\hline Placebo & $8 \cdot 6 \pm 0 \cdot 5$ & $2 \cdot 6 \pm 0 \cdot 3$ & $172 \pm 43$ & $24 \pm 14$ & 8 \\
\hline Acarbose $50 \mathrm{mg}$ & $7 \cdot 2 \pm 0 \cdot 4 \dagger$ & $3 \cdot 2 \pm 0 \cdot 2 \dagger$ & $124 \pm 41$ & $64 \pm 21^{*}$ & $2^{*}$ \\
\hline Acarbose $100 \mathrm{mg}$ & $7 \cdot 0 \pm 0 \cdot 5 \dagger$ & $3 \cdot 2 \pm 0 \cdot 3$ & $120 \pm 40$ & $86 \pm 19^{*}$ & $2^{*}$ \\
\hline Pectin $4.2 \mathrm{~g}$ & $8 \cdot 3 \pm 0 \cdot 5$ & $2 \cdot 9 \pm 0 \cdot 2$ & $150 \pm 36$ & $24 \pm 19$ & 5 \\
\hline Acarbose $50 \mathrm{mg}+$ pectin $4.2 \mathrm{~g}$ & $7 \cdot 2 \pm 0 \cdot 6 \dagger$ & $3 \cdot 4 \pm 0 \cdot 2^{*}$ & $102 \pm 17^{*}$ & $61 \pm 18^{*}$ & $2^{*}$ \\
\hline
\end{tabular}

Asterisks indicate significant differences from placebo $\left({ }^{*} \mathrm{p}<0.05 ; \mathrm{p}<0.01\right)$.

Glucose: $1 \mathrm{mmol} / 1=18.2 \mathrm{mg} / 100 \mathrm{ml}$. Insulin: $1 \mu \mathrm{U} / \mathrm{ml}=7 \cdot 2 \mathrm{pmol} / \mathrm{l}$.

significantly reduced the plasma glucose peak to $7.2 \pm 0.4 \mathrm{mmol} / \mathrm{l} \quad(\mathrm{p}<0.01)$ and it increased the plasma glucose nadir to $3 \cdot 2 \pm 0 \cdot 2 \mathrm{mmol} / \mathrm{l}(\mathrm{p}<0 \cdot 01)$. In the two patients with severe hypoglycaemia of $1 \cdot 1$ and $1.4 \mathrm{mmol} / \mathrm{l}$ the plasma glucose nadir increased to $2.6 \mathrm{mmol} / \mathrm{l}$. The peak plasma insulin concentrations were not significantly reduced by $50 \mathrm{mg}$ acarbose, although plasma insulin peaks in all patients were less than $250 \mu \mathrm{U} / \mathrm{ml}$. This treatment induced a significant rise in breath hydrogen excretion $(p<0.05)$; five of the nine patients had a rise in breath hydrogen excretion of more than 25 ppm (Figure; Table).

Increasing the dose of acarbose to $100 \mathrm{mg}$ did not lead to better results than those obtained with $50 \mathrm{mg}$ acarbose. Symptoms of reactive hypoglycaemia were present in two of the patients $(p<0.05)$. The peak plasma glucose concentration was inhibited to $7.0 \pm 0.5 \mathrm{mmol} / \mathrm{l}(\mathrm{p}<0.01)$ and the nadir was increased to $3 \cdot 2 \pm 0 \cdot 3 \mathrm{mmol} / \mathrm{l}$ (ns). Peak plasma insulin concentrations were not significantly inhibited and were in the same range as after $50 \mathrm{mg}$ acarbose. Excretion of breath hydrogen was significantly increased compared with placebo $(\mathrm{p}<0.05)$, but the expiratory hydrogen excretion after $100 \mathrm{mg}$ acarbose was not significantly higher than after 50 $\mathrm{mg}$ acarbose; six patients had increases in hydrogen excretion of more than $75 \mathrm{ppm}$, while the remaining three patients had normal responses of less than 25 ppm.

After addition of $4.2 \mathrm{~g}$ pectin to the meal five of the patients had hypoglycaemic symptoms (ns). The plasma glucose peak and nadir were not significantly influenced to $8.3 \pm 0.55 \mathrm{mmol} / \mathrm{l}$ and to $2.9 \pm 0.2$ $\mathrm{mmol} / \mathrm{l}$, respectively. Peak plasma insulin concentrations were almost unaffected by this dose of pectin. There was no influence on breath hydrogen excretion.

The combination of $50 \mathrm{mg}$ acarbose with $4.2 \mathrm{~g}$ pectin gave no better results than those obtained with $50 \mathrm{mg}$ acarbose. Two patients had symptoms suggestive of reactive hypoglycaemia $(\mathrm{p}<0.05)$. The plasma glucose peak was reduced to $7 \cdot 2 \pm 0.6 \mathrm{mmol} / \mathrm{l}$ $(p<0.01)$ and the nadir was increased to $3.4 \pm 0.2$ $\mathrm{mmol} / \mathrm{l}(\mathrm{p}<0.05)$. The combination of acarbose with pectin was the only treatment which significantly reduced the plasma insulin peak $(p<0.05$; Table). All peak plasma insulin concentrations were reduced to less than $200 \mu \mathrm{U} / \mathrm{ml}$ (Figure). The rise in breath hydrogen excretion was significantly increased compared with placebo $(\mathrm{p}<0.05)$ and did not differ from the results obtained with $50 \mathrm{mg}$ acarbose.

\section{Discussion}

Acarbose is a recently developed $\alpha$-glucoside hydrolase inhibitor of microbial origin. ${ }^{5,19}$ After ingestion it inhibits digestion of starch and sucrose and it therefore delays absorption of carbohydrate. By preventing the rapid rise in blood glucose with subsequent hyperinsulinism and hypoglycaemia after ingestion of carbohydrate, acarbose might be of value in the treatment of reactive hypoglycaemia in patients with gastric surgery. This favourable effect in patients with postprandial reactive hypoglycaemia was recently substantiated, when McLoughlin et al $^{4}$ showed that $100 \mathrm{mg}$ acarbose ingested before an oral dose of $50 \mathrm{~g}$ sucrose significantly improved symptoms. In that study it was further shown that acarbose attenuated the plasma glucose curve and inhibited the plasma insulin peak. The present study differs considerably from McLoughlin's study in the following respects: (1) a $50 \mathrm{mg}$ and a $100 \mathrm{mg}$ dose of acarbose were studied, (2) a normal carbohydrate rich breakfast was ingested, (3) the patients had more severe postprandial hypoglycaemia, (4) a combination of acarbose with pectin was also studied, and (5) end-expiratory breath hydrogen concentrations 
were measured. Furthermore, we have compared the results with those of $4.2 \mathrm{~g}$ pectin. This dose of pectin, administered in six large capsules, is much lower than in most previous studies. In most studies about $15 \mathrm{~g}$ pectin is mixed with a glucose solution, , $32-14$ while in some studies about $10 \mathrm{~g}$ pectin was added to a glucose solution or to marmalade in a meal. ${ }^{15-17}$ Despite several studies on the effects of pectin in patients with previous gastric surgery, $3,14,17$ to our knowledge, no studies on long term effects of pectin have been reported. This is probably owing to the difficulties that patients have in taking these large amounts of pectin for months to years. Pectin is unpalatable if it is not packed in capsules or sachets or added to sugar solutions or marmalade. We felt that administration of $4.2 \mathrm{~g}$ pectin in six large capsules containing $0.7 \mathrm{~g}$ each with meals is the maximal amount of pectin which might be tolerated by patients in the long run. It should be realised that the availability of pectin might have been reduced by the capsule form, but it has been shown that the wall of a capsule is completely destroyed within 10 to 15 minutes after ingestion. ${ }^{18}$

The present study showed that $50 \mathrm{mg}$ acarbose reduced hypoglycaemic symptoms after a carbohydrate rich breakfast. Furthermore, this treatment significantly attenuated the glucose curve and it slightly inhibited the plasma insulin peak. Fifty milligrams acarbose, however, induced significant rises in breath hydrogen excretion. These rises in expiratory hydrogen excretion are because of malabsorption of carbohydrate which may lead to side-effects, such as borborygmia, meteorismus or flatulence. After the meal six patients on $50 \mathrm{mg}$ acarbose and seven patients on $100 \mathrm{mg}$ acarbose had complaints of carbohydrate malabsorption, while three patients had such complaints on placebo. In contrast with our results in postgastrectomy patients, oral administration of $50 \mathrm{mg}$ acarbose with $50 \mathrm{~g}$ sucrose to normal subjects did not result in significant rises in expiratory hydrogen excretion. ${ }^{6}$ Patients with previous gastric surgery seem to be prone to carbohydrate malabsorption, as three of nine patients in our study had an abnormally high rise in breath hydrogen excretion after the breakfast and placebo. It has previously been found that 14.5 $\mathrm{g}$ pectin added to a glucose solution inhibits the rise in expiratory hydrogen excretion in patients after gastric surgery. ${ }^{3}$ In the present study, however, a low dose of pectin did not influence postprandial breath hydrogen excretion. Furthermore, addition of pectin to $50 \mathrm{mg}$ acarbose did not inhibit the increased postprandial expiratory hydrogen concentrations induced by the $50 \mathrm{mg}$ acarbose treatment.

Results with $100 \mathrm{mg}$ acarbose were not better than with $50 \mathrm{mg}$ acarbose. The addition of $4.2 \mathrm{~g}$ pectin to $50 \mathrm{mg}$ acarbose did not significantly improve the results. It might be argued that a dose of $4.2 \mathrm{~g}$ pectin is too low to promote the effect of $50 \mathrm{mg}$ acarbose. Studies of larger doses of pectin, however, added to $50 \mathrm{mg}$ acarbose are of limited value, as patients will be unlikely to comply with such a treatment in the long term.

In summary, this study showed that $50 \mathrm{mg}$ acarbose ingested with a carbohydrate rich meal improved symptoms of reactive hypoglycaemia in patients with previous gastric surgery. This improvement in clinical symptoms was accompanied by an attenuation of the glucose curve and a tendency to decrease plasma insulin concentrations. Addition of $4.2 \mathrm{~g}$ pectin to the same meal did not significantly improve clinical symptoms or laboratory measurements. A dose of $100 \mathrm{mg}$ acarbose or the combination of $50 \mathrm{mg}$ acarbose with $4.2 \mathrm{~g}$ pectin did not lead to better results than those obtained with $50 \mathrm{mg}$ acarbose. All treatments with acarbose induced significant increases in breath hydrogen excretion. Long-term studies on $50 \mathrm{mg}$ acarbose with daily meals in patients with postprandial reactive hypoglycaemia after gastric surgery have to be performed in order to determine whether the improvement of symptoms persists and whether the side-effects are acceptable.

The authors are indebted to Professors T J Benraad and $\mathrm{A}$ P Jansen for laboratory measurements, and to Miss H J M Lamers, dietition, for her advice. Acarbose was obtained from $\mathrm{Dr} \mathrm{J} \mathrm{H}$ Branolte, Medical Department, Bayer, Mijdrecht, The Netherlands.

This paper was presented at the autumn meeting of the British Society of Gastroenterology, Exeter, September 1981.

\section{References}

1 Smith FW, Jeffries GH. Late and persistent postgastrectomy problems. In: Sleisenger MH, Fordtran JS eds. Gastrointestinal diseases. Philadelphia: Saunders, 1973: 822-8.

2 Woodward ER, Neustein CL. The late postprandial dumping syndrome. In: Bushkin FL, Woodward ER eds. Postgastrectomy syndromes. Philadelphia: Saunders, 1976: 28-33.

3 Jenkins DJA, Gassull ME, Leeds AR et al. Effect of 
dietary fiber on complications of gastric surgery: prevention of postprandial hypoglycemia by pectin. Gastroenterology 1977; 72: 215-7.

4 McLoughlin JC, Buchanan KD, Alam MJ. A glucoside-hydrolase inhibitor in treatment of dumping syndrome. Lancet 1979; 2: 603-5.

5 Caspary WF. Sucrose malabsorption in man after ingestion of $\alpha$-glucosidehydrolase inhibitor. Lancet 1978; 1: 1231-3.

6 Jenkins DJA. Taylor RH. Nineham R et al. Combined use of guar and acarbose in reduction of postprandial glycemia. Lancet 1979: 2: 924-7.

7 Hoffman WS. A rapid photoelectric method for the determination of glucose in blood and urine. $J$ Biol Chem 1937; 120: 51-5.

8 Yalow RS. Berson SA. Immunoassay of endogenous plasma insulin in man. J. Clin Invest 1960; 39: 1157-75.

9 Metz G, Gassull MA, Leeds AR, Blendis LM, Jenkins DJA. A simple method of measuring breath hydrogen in carbohydrate malabsorption by end-expiratory sampling. Clin Sci Mol Med 1976; 50: 237-40.

10 Siegel S. Non-parametric statistics. Tokyo-London: McGraw-Hill Kogakusha, 1956.

11 Schmidt DD, Frommer W, Junge B, Müller L, Wingender W, Truscheit E. $\alpha$-glucosidase inhibitors; new complex oligosaccharides of microbial origin.
Naturwissenschaften 1977; 64: S535.

12 Holt S, Heading RC, Carter DC, Prescott LF, Tothill P. Effect of gel fibre on gastric emptying and absorption of glucose and paracetamol. Lancet 1979; 1: 636-9.

13 Jenkins DJA, Wolever TMS, Leeds AR et al. Dietary fibres, fibre analogues, and glucose tolerance: importance of viscosity. Br Med J 1978; 1: 1392-4.

14 Jenkins DJA, Bloom SR, Albuquerque RH et al. Pectin and complications after gastric surgery: normalisation of postprandial glucose and endocrine responses. Gut 1980; 21: 574-9.

15 Jenkins DJA, Goff DV, Leeds AR et al. Unabsorbable carbohydrates and diabetes: decreased postprandial hyperglycemia. Lancet 1976; 2: 172-4.

16 Jenkins DJA, Leeds AR, Gassull MA, Cochet B, Alberti KGMM. Decrease in postprandial insulin and glucose concentrations by guar and pectin. Ann Intern Med 1977; 86: 20-3.

17 Leeds AR, Ralphs DNL, Ebied F, Metz G, Dilawari JB. Pectin in the dumping syndrome: reduction of symptoms and plasma volume changes. Lancet 1981; 1: 1075-8.

18 Ludwig A, De Beukelaer P, Van Ooteghem M. Afgifte van geneesmiddelen verpakt in harde gelatinecapsules. Pharm Weekblad 1980; 115: 1461-7. 